\title{
Erratum to: Mechano-signaling in heart failure
}

\author{
Byambajav Buyandelger • Catherine Mansfield • \\ Ralph Knöll
}

Published online: 3 July 2014

(C) Springer-Verlag Berlin Heidelberg 2014

Erratum to: Pflugers Arch - Eur J Physiol (2014) 466:1093-1099

DOI 10.1007/s00424-014-1468-4

\begin{abstract}
Acknowledgements / Sources of Funding Dr. R. Knöll is supported by DFG Kn 448/9-1, DFG Kn 448 10-2, Fritz Thyssen Stiftung, British Heart Foundation (PG11/34/28793), FP7-PEOPLE-2011-IRSES, Proposal No 291834 - Acronym: SarcoSi and the Fondation Leducq (13CVD04).
\end{abstract}

The online version of the original article can be found at http://dx.doi.org/ 10.1007/s00424-014-1468-4.

B. Buyandelger · C. Mansfield · R. Knöll $(\square)$

Imperial College, British Heart Foundation - Centre for Research Excellence, National Heart and Lung Institute, Imperial Centre for Translational and Experimental Medicine, Hammersmith Campus, Du Cane Road, London W12 0NN, UK

e-mail: r.knoell@imperial.ac.uk 